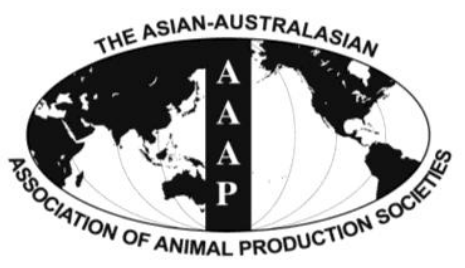

Asian-Aust. J. Anim. Sci.

Vol. 26, No. 4 : 501-508 April 2013

http://dx.doi.org/10.5713/ajas.2012.12567

www.ajas.info

pISSN 101 1-2367 elSSN 1976-5517

\title{
Effect of Dipeptides on In vitro Maturation, Fertilization and Subsequent Embryonic Development of Porcine Oocytes
}

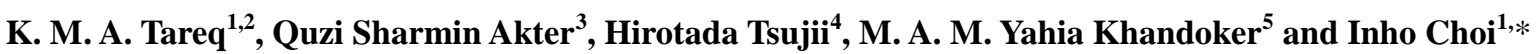 \\ ${ }^{1}$ School of Biotechnology, Yeungnam University, Gyeongsan 712-749, Korea
}

\begin{abstract}
The effects of amino acids and dipeptides on in vitro production of porcine embryos and accumulation of ammonia in culture medium during developmental stages were examined in this study. The maturation, fertilization and development of embryonic cultures were performed in modified Tissue culture medium (mTCM)-199 supplemented with 10\% (v/v) porcine follicular fluid, modified Tyrode's albumin lactate pyruvate (mTALP) medium, and modified North Carolina State University (mNCSU)-23 medium, respectively. In addition, amino acids and dipeptides of different concentrations and combinations were used to treat the embryos. The addition of L-alanyl-L-glutamine (AlnGln)+L-glycyl-L-glutamine (GlyGln) significantly $(\mathrm{p}<0.05)$ improved oocyte maturation, fertilization and the incorporation and oxidation of ${ }^{14} \mathrm{C}(\mathrm{U})$-glucose when compared to the control group and other treatment groups. Additionally, 2-4 cell, 8-16 cell, morula and blastocyst development increased significantly $(\mathrm{p}<0.05)$ following treatment with AlnGln+GlyGln when compared to the control group and other treatment groups, while this treatment reduced the accumulation of ammonia. Taken together, these findings suggest that treatment with AlnGln+GlyGln may play an important role in increasing the rate of porcine oocyte maturation, fertilization and embryonic development by reducing the level of accumulated ammonia measured in the culture media. (Key Words: Ammonia Accumulation, Dipeptides, Incorporation and Oxidation, Porcine Embryos)
\end{abstract}

\section{INTRODUCTION}

In vitro maturation (IVM) and in vitro fertilization (IVF) of porcine oocytes have been extensively investigated. Oocyte maturation is a critical step in in vitro production systems because it influences oocyte quality, which subsequently affects embryonic development, fetal development, and even the health of the offspring (Eppig and O'Brien, 1998). However, oocytes that mature in vitro have decreased developmental competence when compared to oocytes matured in vivo, indicating that IVM systems are

\footnotetext{
* Corresponding Author: I. Choi. Tel: +82-53-810-3024, Fax: +82-53-810-4769, E-mail: inhochoi@ynu.ac.kr

${ }^{2}$ Faculty of Animal Science and Veterinary Medicine, Patuakhali Science and Technology University, Barisal-8210, Bangladesh.

3 Department of Animal Breeding and Genetics, Faculty of Animal Science and Veterinary Medicine, Patuakhali Science and Technology University, Barisal-8210, Bangladesh.

${ }^{4}$ Department of Bioscience and Biotechnology, Faculty of Agriculture, Shinshu University, Minamiminowa-mura, Naganoken 399-4598, Japan.

${ }^{5}$ Department of Animal Breeding and Genetics, Bangladesh Agricultural University, Mymensingh-2202, Bangladesh. Submitted Oct. 8, 2012; Accepted Dec. 10, 2012; Revised Jan. 9, 2013
}

still suboptimal. Therefore, optimization of currently available maturation medium is important to increase the efficiency of IVM systems.

Amino acids are included in the majority of culture media for both oocyte maturation and embryonic culture because they serve a variety of physiological functions including protein and nucleotide synthesis (Epstein and Smith, 1973; Alexiou and Leese, 1992), provision of energy sources (Gardner, 1998), protection against osmotic shock (Lane, 2001) with oxidative stress (Lindenbaum, 1973), and regulation of $\mathrm{pH}$ (Edwards et al., 1998). Spontaneous degradation and catabolism of amino acids, particularly glutamine (Gln), can result in the production of ammonia (Gardner and Lane, 1993), which is toxic to living cells both in vivo (Prior and Visek, 1972) and in vitro (Visek et al., 1972). The presence of ammonia in culture medium results in a reduction of intracellular $\mathrm{pH}$, depression of oxidative phosphorylation (Lane et al., 2002), decreased blastocyst cell numbers (Gardner and Lane, 1993), increased cellular apoptosis, perturbation of Slc $2 a 3$ expression and glucose uptake (Zander et al., 2006), and eventually altered fetal development and growth rates (Sinclair et al., 1998) as well as fetal exencephaly (Lane and Gardner, 1994). 
The toxic effects of Gln can be avoided by adding dipeptides into the culture media for direct use by mammalian cells in vitro (Eagle, 1955). It has been suggested that Gln could be replaced with L-alanyl-Lglutamine (AlnGln) and L-glycyl-L-glutamine (GlyGln) to achieve an increased level of embryonic deployment in mice (Biggers, 2004). We previously reported that the accumulation of ammonia in the medium could be reduced by supplementation with seleon L-methionine (SeMet) and SeMet+Vitamin-E (Tareq et al., 2012). Dipeptides play an important role in oocyte maturation (Tareq et al., 2007) and the porcine sperm acrosome reaction (Tareq et al., 2008). Although a number of studies have shown the importance of dipeptides in embryo development, the direct effects of GlyGln and AlaGln on the accumulation of ammonia in culture media and in vitro porcine embryo development have not yet been definitively demonstrated. Therefore, this study was conducted to investigate the effects of Gln, glutamic acid (Glu), GlyGln and AlaGln on embryo development and accumulation of ammonia in the medium during in vitro maturation, fertilization, and development of porcine embryos.

\section{MATERIAL AND METHODS}

\section{Chemicals}

Radioactive ${ }^{14} \mathrm{C}(\mathrm{U})$-glucose was purchased from American Radiolabeled Chemicals, Inc. (St. Louis, MO, USA). Gln, Glu, GlyGln, AlaGln and all other chemicals were of analytical grade and purchased from Nacalai Tesque (Kyoto, Japan), unless otherwise indicated.

\section{Oocyte recovery and in vitro maturation}

Ovaries were collected from gilts (Landrace, Large White and Duroc) at a local slaughterhouse and transported to the laboratory in physiological saline supplemented with $100 \mathrm{IU} / \mathrm{ml}$ Penicillin G and $100 \mathrm{mg} / \mathrm{ml}$ Streptomycin sulfate at 30 to $35^{\circ} \mathrm{C}$ within 1 to $3 \mathrm{~h}$ of collection. Cumulus-oocyte complexes (COCs) from follicles 3 to $6 \mathrm{~mm}$ in diameter were aspirated using an 18-gauge needle attached to a $10 \mathrm{ml}$ disposable syringe. Intact COCs were selected using mouth pipettes and washed three times in HEPES-buffered North Caroline State University medium in glutamine and glucose-free (NCSU)-23 supplemented with $0.3 \%$ bovine serum albumin (BSA). Washed COCs were transferred to IVM medium consisting of modified Tissue culture medium (mTCM)-199 supplemented with $10 \mathrm{ng} / \mathrm{ml}$ epidermal growth factor (EGF), $4 \mathrm{IU} / \mathrm{ml}$ pregnant mare serum gonadotropin (PMSG; Sankyo Zoki, Tokyo, Japan) and human chorionic gonadotropin (hCG; Sankyo Zoki, Tokyo, Japan), and $10 \%(\mathrm{v} / \mathrm{v})$ porcine follicular fluid $(\mathrm{pFF})$. The $\mathrm{pFF}$ was collected from antral follicles of prepubescent gilts, centrifuged at $1,600 \times \mathrm{g}$ for $30 \mathrm{~min}$ and filtered through both
1.2 and $0.45-\mu \mathrm{m}$ syringe filters (Toyo Roshi Kaisha, Ltd., Tokyo, Japan). The filtered $\mathrm{pFF}$ was stored in aliquots at $20^{\circ} \mathrm{C}$ for further use. Fifty COCs in $500 \mu \mathrm{l}$ of IVM medium were cultured at $39^{\circ} \mathrm{C}$ under $5 \% \mathrm{CO}_{2}$ in air. After culturing for $22 \mathrm{~h}, \mathrm{COCs}$ were washed three times and cultured in PMSG and hCG-free mTCM-199 medium for an additional $22 \mathrm{~h}$ at $39^{\circ} \mathrm{C}$ under $5 \% \mathrm{CO}_{2}$ in air.

\section{Sperm preparation and in vitro fertilization}

Ejaculated sperm were obtained from Duroc boars and diluted according to the method described by Johnson et al. (1988). After being washed three times by centrifugation at $900 \times \mathrm{g}$ for $5 \mathrm{~min}$ each, the sperm pellet was resuspended in in vitro fertilization medium, which consisted of modified Tyrode's albumin lactate pyruvate (mTALP) medium (Parrish et al., 998) containing $3 \mathrm{mg} / \mathrm{ml} \mathrm{BSA}$ and $2 \mathrm{mM}$ caffeine to give a final concentration of $2 \times 10^{6}$ spermatozoa/ml (Tareq et al., 2007). The oocytes and spermatozoa were co-cultured for $6 \mathrm{~h}$ at $39^{\circ} \mathrm{C}$ in an atmosphere of $5 \% \mathrm{CO}_{2}$ in air. At $44 \mathrm{~h}$ of maturation, oocytes were freed from cumulus cells by repeated pipetting in $0.1 \%$ hyaluronidase in mTCM-199 medium and then washed three times with pre-equilibrated mTALP. After washing, 20 to 25 oocytes were placed in $45 \mu \mathrm{l}$ drops of the mTALP (fertilizing drop). The samples were then covered with pre-warmed paraffin oil and $5 \mu \mathrm{l}$ of sperm suspension was added to each fertilization drop to give a final sperm concentration of $2 \times 10^{6} \mathrm{sperm} / \mathrm{ml}$. After co-incubation of gametes for $6 \mathrm{~h}$, the presumptive zygotes were washed and transferred into culture (IVC) medium.

\section{Embryo culture}

After IVF, COCs were washed several times in a fertilization drop to remove spermatozoa loosely attached to inseminated oocytes and then washed a final time in glutamine and glucose-free modified North Carolina State University (mNCSU)-23 (Petters and Reed, 1991) medium containing $0.5 \mathrm{mM}$ sodium pyruvate, $5 \mathrm{mM}$ sodium lactate, and $0.4 \%$ BSA (A-6003, fraction V). Ten to fifteen putative zygotes were then freed from cumulus cells and transferred to a $30 \mu \mathrm{l}$ microdrop of culture medium covered with warm mineral oil. Embryos were cultured for up to $168 \mathrm{~h}$ after IVF in a humidified atmosphere of $39^{\circ} \mathrm{C}$ and $5 \% \mathrm{CO}_{2}$ in air without any replacement with fresh medium (Hashem et al., 2006).

\section{Assessment of meiotic maturation, sperm penetration and embryo cell number}

Oocyte maturation, fertilization, cleavage and blastocyst formation and blastomere number in blastocysts were examined at $44 \mathrm{~h}$ after IVM and at 12, 48, and $168 \mathrm{~h}$ after IVF, respectively. At the time of examination, oocytes or 
blastocysts were mounted on a glass slide and fixed for 10 $\min$ in $25 \%(\mathrm{v} / \mathrm{v})$ acetic acid in ethanol. Fixation was carried out on a $33.8^{\circ} \mathrm{C}$ warm plate for the removal of lipids within $10 \mathrm{~min}$. The samples were then stained with $1 \%$ $(\mathrm{w} / \mathrm{v})$ orcein in $45 \%(\mathrm{v} / \mathrm{v})$ acetic acid solution and examined under a phase-contrast microscope (IX-50, Olympus, Tokyo, Japan) at $400 \times$. The meiotic stage of the oocytes was assessed according to the methods described by Hunter and Polge (1966) and oocytes at the metaphase II (MII) stage were regarded as mature. Oocytes were considered to be penetrated when they contained one or more swollen sperm heads or male pronuclei with corresponding sperm tails.

\section{Differential staining}

The quality of blastocysts was assessed by differential staining of the inner cell mass (ICM) and trophectoderm (TE) cells according to the modified staining procedure described by Thouas et al. (2001). Briefly, hatched blastocysts were left untreated, and unhatched blastocysts were treated with $0.25 \%$ pronase (w/v, Sigma-Aldrich, St. Louis, MO, USA) for $5 \mathrm{~min}$ to dissolve the zonae pellucidae. After rinsing in mNCSU-23 medium, zona-free blastocysts were stained with $0.01 \%(\mathrm{w} / \mathrm{v})$ bisbenzimide for $1 \mathrm{~h}$. The blastocysts were then rinsed in mNCSU-23 medium again and treated with $0.04 \%$ (v/v) Triton X-100 (Sigma-Aldrich) for $3 \mathrm{~min}$ followed by treatment with $0.005 \%(\mathrm{w} / \mathrm{v})$ propidium iodide (Sigma-Aldrich) for $10 \mathrm{~min}$. After another rinse in mNCSU-23 medium, stained blastocysts were mounted on glass slides under a cover slip and examined with an inverted microscope (Nikon Corp., Tokyo, Japan) equipped with epifluorescence. The ICM nuclei labeled with bisbenzimide appeared blue, and the TE cell nuclei labeled with both bisbenzimide and propidium iodide appeared pink. Blastocysts without dual staining were excluded from the study (Thouas et al., 2001).

\section{Incorporation and oxidation of radiolabeled glucose}

The radioactive substrates, ${ }^{14} \mathrm{C}(\mathrm{U})$-glucose (specific activity: $185 \mathrm{MBq} / \mathrm{mM}$ ), were produced as described in our previous study (Tsujii et al., 2009). All scintillation vials and three blanks for each group were filled with $5 \mathrm{ml}$ of cocktail and then set in a liquid scintillation counter (LS6500, Beckman-Coulter, CA, USA) to determine the levels of radioactivity. This experiment was conducted five times to improve its accuracy. All values of incorporation and oxidation are expressed directly as counts per min (cpm) (Tsujii et al., 2002).

\section{Ammonia assay}

The ammonia concentrations in the medium were assessed using the Berthelot-indophenol method as previously described (Tareq et al., 2005). This method was further used to analyze the maturation at the MII stage within $44 \mathrm{~h}$, fertilization for $6 \mathrm{~h}$ and culture of oocytes, cleavage to the 2-cell stage at $48 \mathrm{~h}$ and the blastocyst stage at $168 \mathrm{~h}$. After completion of the stages mentioned above, $50 \mu \mathrm{l}$ of the culture medium was immediately sampled to measure the concentration of ammonia. This procedure was performed five times for each analysis. A calibration curve in the range of 0 to $0.40 \mathrm{mM}$ ammonia was run for each experiment and the mean correlation coefficient for the calibration curves of five experiments was 0.995 .

\section{Experimental design}

In this study, various combinations of the optimal concentration of Gln, Glu, GlyGln and AlaGln were used to examine the effects of mTCM-199 on IVM for $44 \mathrm{~h}$, the effects of mTALP on IVF for $6 \mathrm{~h}$ and the effects of mNCSU-23 on IVC for $168 \mathrm{~h}$. Finally, the incorporation and oxidation of the ${ }^{14} \mathrm{C}(\mathrm{U})$-glucose, accumulation of ammonia after IVM, IVF and IVC and number of cells within blastocysts were investigated. After supplementation with all chemicals, the $\mathrm{pH}$ and osmolarity of each media was adjusted to 7.4 and $270 \mathrm{mOsm}$.

\section{Statistical analysis}

Oocytes were randomly distributed within each experimental group, and each experiment was repeated five times. Arcsine-transformed percentages of replications for rates of maturation, fertilization and embryonic development (Snedecor and Cochran, 1989) and data for the mean number of cells per blastocyst were subjected to ANOVA using the GLM procedures of the Statistical Analysis System (SAS Institute, Inc., Cary, NC, USA) and then analyzed by the Duncan's multiple range test. A p $<0.05$ was considered to indicate statistical significance.

\section{RESULTS}

The percentage of oocyte development to the MII stage, monospermic fertilization and male pronuclear formation increased significantly $(\mathrm{p}<0.05)$ when oocytes were treated with AlaGln, GlyGln and AlaGln+GlyGln when compared to the control and other treatments groups (Table 1). Among this specific treatment subset, the percentage of oocytes developing to the MII stage, monospermic fertilization and male pronuclear formation increased significantly $(\mathrm{p}<0.05)$ when oocytes were treated with AlaGln+GlyGln when compared to treatment with AlaGln and GlyGln. However, there was no significant difference between treatment with Gln, Glu and Gln+Glu in terms of the rates of maturation and fertilization.

The incorporation and oxidation rates of ${ }^{14} \mathrm{C}(\mathrm{U})$-glucose were significantly higher $(\mathrm{p}<0.05)$ in oocytes treated with AlaGln+GlyGln than in those of the control group during maturation and fertilization (Table 2); therefore, there was 
Table 1. Effects of glutamine (Gln), glutamic acid (Glu), L-alayl-L-glutamine (AlaGln), L-glycyl-L-glutamine (GlyGln) and their combinations on the percentage of maturation and fertilization of porcine oocytes

\begin{tabular}{|c|c|c|c|c|c|c|c|c|}
\hline \multirow{2}{*}{ Treatment } & \multicolumn{4}{|c|}{ Maturation $(\%)^{1}$} & \multicolumn{4}{|c|}{ Fertilization $(\%)^{1}$} \\
\hline & $\mathrm{n}$ & Degenerated & Germinal vesicle & Metaphase II & $\mathrm{n}$ & Penetration $^{2}$ & Monospermic $^{3}$ & $\mathrm{MPN}^{4}$ \\
\hline Control (0) & 221 & (27) $12.21 \pm 1.33^{\mathrm{b}}$ & (34) $15.38 \pm 0.79^{\mathrm{a}}$ & (160) $72.39 \pm 1.29^{d}$ & 185 & (120) $65.00 \pm 2.31^{\mathrm{d}}$ & (102) $55.33 \pm 1.93^{\mathrm{e}}$ & (80) $43.16 \pm 1.65^{\mathrm{de}}$ \\
\hline $\operatorname{Gln}(1.0 \mathrm{mM})$ & 210 & (35) $16.58 \pm 0.33^{\mathrm{a}}$ & (28) $13.27 \pm 0.71^{\mathrm{b}}$ & (147) $69.66 \pm 1.32^{\mathrm{ef}}$ & 172 & (107) $62.46 \pm 1.32^{\mathrm{e}}$ & (99) $57.70 \pm 3.10^{\mathrm{e}}$ & (78) $45.16 \pm 1.82^{\mathrm{d}}$ \\
\hline Glu $(1.0 \mathrm{mM})$ & 198 & (36) $17.91 \pm 1.25^{\mathrm{a}}$ & (25) $12.43 \pm 0.88^{\mathrm{bc}}$ & (137) $68.15 \pm 1.50^{\mathrm{f}}$ & 198 & (115) $58.16 \pm 1.85^{\mathrm{f}}$ & (123) $62.33 \pm 1.33^{\mathrm{d}}$ & (81) $41.26 \pm 1.30^{\mathrm{e}}$ \\
\hline AlaGln $(2.0 \mathrm{mM})$ & 230 & (15) $6.52 \pm 1.47^{\mathrm{c}}$ & (26) $11.30 \pm 1.42^{\mathrm{cd}}$ & $82.17 \pm 1.40^{\mathrm{c}}$ & 122 & (87) $71.37 \pm 2.00^{\mathrm{c}}$ & (80) $65.30 \pm 2.43^{\mathrm{c}}$ & (92) $75.33 \pm 2.00^{\mathrm{b}}$ \\
\hline GlyGln $(2.0 \mathrm{mM})$ & 200 & (8) $3.98 \pm 0.65^{\mathrm{d}}$ & (21) $10.44 \pm 0.85^{\mathrm{de}}$ & (171) $85.07 \pm 1.70^{\mathrm{b}}$ & 135 & (100) $74.36 \pm 2.30^{\mathrm{b}}$ & (92) $68.63 \pm 1.85^{\mathrm{b}}$ & (102) $75.66 \pm 1.20^{b}$ \\
\hline $\begin{array}{l}\text { AlaGln+GlyGln } \\
(2.0+2.0 \mathrm{mM})\end{array}$ & 196 & (5) $3.59 \pm 1.53^{\mathrm{d}}$ & (20) $10.36 \pm 1.38^{\mathrm{bc}}$ & (171) $88.60 \pm 1.13^{\mathrm{a}}$ & 155 & (120) $77.33 \pm 1.20^{\mathrm{a}}$ & (110) $71.00 \pm 1.60^{\mathrm{a}}$ & (124) $80.16 \pm 3.00^{\mathrm{a}}$ \\
\hline $\begin{array}{l}\mathrm{Gln}+\mathrm{Glu} \\
\quad(1.0+1.0 \mathrm{mM})\end{array}$ & 204 & (38) $18.26 \pm 0.95^{\mathrm{a}}$ & (20) $9.61 \pm 1.15^{\mathrm{e}}$ & (146) $70.19 \pm 1.30^{\mathrm{e}}$ & 145 & (90) $62.20 \pm 1.65^{\mathrm{e}}$ & (73) $50.90 \pm 1.60^{f}$ & (73) $50.17 \pm 3.00^{\mathrm{c}}$ \\
\hline
\end{tabular}

Within a column, values with different letters (a-f) are significantly different $(\mathrm{p}<0.05)$.

$\mathrm{n}$ : number of oocytes, five replicates.

${ }^{1}$ Percentage of the number of oocytes. ${ }^{2}$ Penetrated oocytes with one first and one second polar body.

${ }^{3}$ With both single male pronuclear (MPN) and female pronuclei. ${ }^{4} \mathrm{MPN}$ indicates male pronucleus or pronuclei.

no significant difference between treatment with Gln, Glu and GIn+Glu when compared with the control group. The accumulation of ammonia in the medium was significantly reduced $(\mathrm{p}<0.05)$ after the addition of AlaGln+GlyGln, with the exception of Gln, Glu and Gln+Glu, when compared with the other treatments groups during maturation and fertilization. The development rates for the 2 to 4 cell, 8 to 16 cell, morula, and blastocyst stages were higher when embryos were treated with AlaGln, GlyGln and AlaGln+GlyGln. In addition, the development rates of the 2 to 4 cell, 8 to 16 cell, morula and blastocyst stages were higher for samples treated with AlaGln+GlyGln than with AlaGln and GlyGln. Gln, Glu and Gln+Glu had no significant $(p<0.05)$ effect on 2 to 4 cell, 8 to 16 cell, morula and blastocyst development when compared to the control group (Table 3 ). The incorporation and oxidation rates of ${ }^{14} \mathrm{C}(\mathrm{U})$-glucose were higher $(\mathrm{p}<0.05)$ in embryos treated with AlaGln+GlyGln at the 2-cell and blastocyst stages than in the control group. The accumulation of ammonia in the culture medium was significantly reduced $(\mathrm{p}<0.05)$ in the presence of AlaGln, GlyGln and AlaGln+GlyGln when compared with those of the other treatment groups. Specifically, treatment with AlaGln+GlyGln had the largest impact on reducing the accumulation of ammonia in the 2-cell and blastocyst stages when compared with those of the control group (Table 4). Moreover, the numbers of ICM and TE cells in the AlaGln, GlyGln and AlaGln+GlyGln treatment groups were found to be significantly higher $(\mathrm{p}<0.05)$ than those in the control group. Finally, more ICM and TE cells were observed in the AlaGln+GlyGln treated embryos than in those in the control group and all other treatment groups (Table 5).

\section{DISCUSSION}

We previously reported that porcine oocyte maturation was adversely affected when $\geq 300 \mu \mathrm{M}$ exogenous ammonia was added to the maturation medium (Tareq et al., 2007). Interestingly, follicular fluid concentrations of ammonia in porcine ranged from $350 \mu \mathrm{M}$ in small follicles (diameter

Table 2. The rates of incorporation and oxidation of ${ }^{14} \mathrm{C}(\mathrm{U})$-glucose and the accumulation of ammonia upon treatment with glutamine (Gln), glutamic acid (Glu), L-alayl-L-glutamine (AlaGln), L-glycyl-L-glutamine (GlyGln) and their combinations on the maturation and fertilization of porcine oocytes

\begin{tabular}{|c|c|c|c|c|c|c|}
\hline \multirow{2}{*}{$\begin{array}{l}\text { Treatment } \\
\mathrm{n}(25)\end{array}$} & \multicolumn{2}{|c|}{$\begin{array}{c}\text { Incorporation of }{ }^{14} \mathrm{C}(\mathrm{U}) \text {-glucose } \\
(\mathrm{cpm} / \text { oocyte })^{3}\end{array}$} & \multicolumn{2}{|c|}{$\begin{array}{c}\text { Oxidation of }{ }^{14} \mathrm{C}(\mathrm{U}) \text {-glucose } \\
(\text { cpm/oocyte })^{3}\end{array}$} & \multicolumn{2}{|c|}{$\begin{array}{l}\text { Ammonia concentration } \\
\qquad(\mu \mathrm{M})^{3}\end{array}$} \\
\hline & Maturation $^{1}$ & Fertilization $^{2}$ & Maturation $^{1}$ & Fertilization $^{2}$ & Maturation $^{1}$ & Fertilization $^{2}$ \\
\hline Control (0) & $2,040.00 \pm 286.88^{\mathrm{de}}$ & $1,631.66 \pm 222.89^{\mathrm{d}}$ & $173.33 \pm 12.41^{\mathrm{c}}$ & $161.00 \pm 23.39^{\mathrm{c}}$ & $190.00 \pm 11.56^{\mathrm{a}}$ & $170.00 \pm 11.55^{\mathrm{ab}}$ \\
\hline $\operatorname{Gln}(1.0 \mathrm{mM})$ & $2,315.67 \pm 176.40^{\mathrm{d}}$ & $1,853.67 \pm 334.34^{\mathrm{d}}$ & $180.33 \pm 34.64^{\mathrm{c}}$ & $181.67 \pm 38.43^{\mathrm{c}}$ & $143.33 \pm 29.06^{\mathrm{ab}}$ & $180.00 \pm 17.32^{\mathrm{a}}$ \\
\hline Glu (1.0 mM) & $2,142.33 \pm 182.01^{\mathrm{de}}$ & $1,740.33 \pm 285.83^{\mathrm{d}}$ & $174.66 \pm 10.41^{\mathrm{c}}$ & $163.00 \pm 24.54^{\mathrm{c}}$ & $180.00 \pm 17.64^{\mathrm{ab}}$ & $166.66 \pm 8.82^{\mathrm{ab}}$ \\
\hline AlaGln $(2.0 \mathrm{mM})$ & $3,920.00 \pm 171.22^{\mathrm{c}}$ & $3,844.67 \pm 109.27^{\mathrm{c}}$ & $303.67 \pm 12.13^{\mathrm{b}}$ & $321.66 \pm 28.29^{\mathrm{b}}$ & $130.00 \pm 11.56^{\mathrm{bc}}$ & $140.00 \pm 11.55^{\mathrm{bc}}$ \\
\hline GlyGln (2.0 mM) & $4,298.00 \pm 394.56^{\mathrm{b}}$ & $4,262.00 \pm 106.04^{b}$ & $314.33 \pm 19.92^{\mathrm{b}}$ & $346.00 \pm 43.88^{\mathrm{ab}}$ & $133.33 \pm 31.79^{\mathrm{bc}}$ & $140.00 \pm 5.77^{\mathrm{bc}}$ \\
\hline AlaGln+GlyGln $(2.0+2.0 \mathrm{mM})$ & $4,787.33 \pm 140.60^{\mathrm{a}}$ & $5,089.66 \pm 74.06^{\mathrm{a}}$ & $449.00 \pm 39.84^{\mathrm{a}}$ & $391.33 \pm 27.55^{\mathrm{a}}$ & $120.00 \pm 11.56^{\mathrm{c}}$ & $110.00 \pm 17.32^{\mathrm{c}}$ \\
\hline Gln+Glu $(1.0+1.0 \mathrm{mM})$ & $1,960.33 \pm 121.64^{\mathrm{e}}$ & $1,941.66 \pm 54.02^{\mathrm{d}}$ & $180.00 \pm 17.32^{\mathrm{c}}$ & $174.00 \pm 13.32^{\mathrm{c}}$ & $186.67 \pm 8.82^{\mathrm{a}}$ & $174.67 \pm 8.84^{\mathrm{a}}$ \\
\hline
\end{tabular}

Within a column, values with different letters $(\mathrm{a}-\mathrm{e})$ are significantly different $(\mathrm{p}<0.05)$.

$\mathrm{n}$ : number of oocytes, five replicates.

${ }^{1}$ Maturation (44 $\mathrm{h}$ incubation period in IVM). ${ }^{2}$ Fertilization ( $6 \mathrm{~h}$ incubation period after IVM).

${ }^{3}$ Mean \pm SEM obtained from the average of each replicate. 
Table 3. Effects of glutamine (Gln), glutamic acid (Glu), L-alayl-L-glutamine (AlaGln), L-glycyl-L-glutamine (GlyGln) and their combinations on the development of porcine embryos

\begin{tabular}{lccccc}
\hline \multirow{2}{*}{ Treatment } & $\mathrm{n}$ & \multicolumn{4}{c}{ Percentages of embryo development (mean \pm SEM) $^{2}$} \\
\cline { 3 - 6 } & & $2-4$ cells $^{1}$ & $8-16$ cells $^{1}$ & Morula $^{1}$ & Blastocyst $^{1}$ \\
\hline Control (0) & 173 & $(122) 71.00 \pm 1.73^{\mathrm{d}}$ & $(111) 64.30 \pm 1.32^{\text {cd }}$ & $(61) 35.23 \pm 1.75^{\mathrm{c}}$ & $(42) 24.00 \pm 1.72^{\text {cd }}$ \\
Gln $(1.0 \mathrm{mM})$ & 160 & $(112) 70.00 \pm 2.89^{\mathrm{d}}$ & $(106) 66.23 \pm 1.18^{\mathrm{c}}$ & $(55) 34.10 \pm 1.16^{\mathrm{c}}$ & $(40) 25.13 \pm 1.74^{\mathrm{c}}$ \\
Glu $(1.0 \mathrm{mM})$ & 170 & $(121) 72.00 \pm 1.15^{\mathrm{d}}$ & $(107) 63.20 \pm 2.89^{\text {cd }}$ & $(61) 36.26 \pm 1.181^{\mathrm{c}}$ & $(37) 22.00 \pm 2.31^{\mathrm{d}}$ \\
AlaGln $(2.0 \mathrm{mM})$ & 154 & $(117) 76.00 \pm 2.31^{\mathrm{c}}$ & $(117) 75.30 \pm 1.76^{\mathrm{b}}$ & $(70) 46.23 \pm 0.91^{\mathrm{b}}$ & $(48) 31.63 \pm 2.34^{\mathrm{b}}$ \\
GlyGln $(2.0 \mathrm{mM})$ & 153 & $(122) 79.00 \pm 2.31^{\mathrm{b}}$ & $(119) 77.93 \pm 2.45^{\mathrm{b}}$ & $(73) 48.02 \pm 1.21^{\mathrm{b}}$ & $(47) 31.36 \pm 1.77^{\mathrm{b}}$ \\
AlaGln+GlyGln $(2.0+2.0 \mathrm{mM})$ & 203 & $(167) 82.16 \pm 1.17^{\mathrm{a}}$ & $(166) 82.13 \pm 1.16^{\mathrm{a}}$ & $(108) 53.03 \pm 1.16^{\mathrm{a}}$ & $(83) 41.23 \pm 1.18^{\mathrm{a}}$ \\
Gln+Glu $(1.0+1.0 \mathrm{mM})$ & 174 & $(124) 72.20 \pm 1.17^{\mathrm{d}}$ & $(108) 62.23 \pm 1.18^{\mathrm{d}}$ & $(60) 34.60 \pm 0.95^{\mathrm{c}}$ & $(45) 25.83 \pm 0.83^{\mathrm{c}}$ \\
\hline
\end{tabular}

Within a column, values with different letters (a-d) are significantly different $(\mathrm{p}<0.05)$.

$\mathrm{n}$ : number of embryos, five replicates.

${ }^{1}$ Embryo development calculated from cleaved embryos. ${ }^{2}$ Mean \pm SEM obtained from the average percentage of each replicate.

$\leq 2 \mathrm{~mm}$ ) to $170 \mu \mathrm{M}$ in large follicles (diameter: 5 to $6 \mathrm{~mm}$ ) (Tareq et al., 2005). These results indicate that the apparent threshold concentration of ammonia toxicity for oocytes from porcine under in vitro conditions (200 to $300 \mu \mathrm{M})$ is greater than the levels oocytes are exposed to as a large follicle during nuclear maturation $(170 \mu \mathrm{M})$.

The present findings demonstrate that the concentrations of ammonia in the culture media during the maturation (120 $\mu \mathrm{M})$, fertilization $(110 \mu \mathrm{M}), 2$-cell $(70 \mu \mathrm{M})$ and blastocyst stages $(100 \mu \mathrm{M})$ were significantly reduced when treated with AlaGln+GlyGln relative to the levels in other treatment groups. The optimal concentration of amino acids and dipeptides used in the present study was similar to the concentration used in studies examining porcine oocytes and sperm (Tareq et al., 2007; 2008). These results indicate that sensitivity to ammonia is dependent on the developmental stage of the oocyte or embryo, and may be related to the presence of cumulus cells. In contrast, in vitro exposure of bovine oocytes to ammonia concentrations up to $400 \mu \mathrm{M}$ for $24 \mathrm{~h}$ IVM did not adversely influence oocyte nuclear maturation, even though concentrations of ammonia in bovine follicular fluid range from $366 \pm 51 \mu \mathrm{M}$ in small follicles (diameter $\leq 1 \mathrm{~mm}$ ) to $33 \pm 10 \mu \mathrm{M}$ in large follicles (diameter: 10 to $15 \mathrm{~mm}$ ) (Hammon et al., 2000). Yuan and Krisher (2010) proposed that the production of ammonia during in vitro oocyte maturation has detrimental effects on the nuclear progression to MII. In addition, the presence of ammonia during embryo culture negatively influences subsequent embryonic development, although parthenogenetic activation embryos appear to be more sensitive to the negative effects of ammonia during oocyte maturation than IVF embryos. In our previous study, the presence of $300 \mu \mathrm{M}$ ammonia in the IVM and IVF medium modified North Carolina State University (mNCSU)-37 of oocytes treated with combinations of dipeptides including AlaGln and GlyGln in the media were found to be more stable and effective than treatment with individual amino acids at reducing the accumulation of ammonia and to increase the rate of porcine oocyte MII and monospermic fertilization in vitro (Tareq et al., 2007). These results

Table 4. The rates of incorporation and oxidation of ${ }^{14} \mathrm{C}(\mathrm{U})$-glucose, and the accumulation of ammonia upon treatment with glutamine (Gln), glutamic acid (Glu), L-alayl-L-glutamine (AlaGln), L-glycyl-L-glutamine (GlyGln) and their combinations in medium on the 2cell and blastocyst stages

\begin{tabular}{|c|c|c|c|c|c|c|}
\hline \multirow{2}{*}{$\begin{array}{l}\text { Treatment } \\
\mathrm{n}(25)\end{array}$} & \multicolumn{2}{|c|}{$\begin{array}{c}\text { Incorporation of }{ }^{14} \mathrm{C}(\mathrm{U}) \text {-glucose } \\
(\mathrm{cpm} / \mathrm{embryo})\end{array}$} & \multicolumn{2}{|c|}{$\begin{array}{l}\text { Oxidation of }{ }^{14} \mathrm{C}(\mathrm{U}) \text {-glucose } \\
(\mathrm{cpm} / \mathrm{embryo})\end{array}$} & \multicolumn{2}{|c|}{$\begin{array}{l}\text { Ammonia concentration } \\
\qquad(\mu \mathrm{M})\end{array}$} \\
\hline & 2-cell & Blastocyst & 2-cell & Blastocyst & 2-cell & Blastocyst \\
\hline Control (0) & $1,283.67 \pm 157.33^{\mathrm{d}}$ & $1,513.33 \pm 170.33^{\mathrm{c}}$ & $230.00 \pm 17.32^{\mathrm{d}}$ & $490.00 \pm 23.09^{\text {cd }}$ & $160.00 \pm 11.56^{\mathrm{ab}}$ & $171.67 \pm 6.01^{\mathrm{ab}}$ \\
\hline $\operatorname{Gln}(1.0 \mathrm{mM})$ & $1,182.02 \pm 136.83^{\mathrm{d}}$ & $1,338.00 \pm 118.62^{\mathrm{c}}$ & $323.00 \pm 12.70^{\mathrm{bc}}$ & $450.66 \pm 22.81^{\mathrm{d}}$ & $173.33 \pm 12.01^{\mathrm{a}}$ & $178.33 \pm 9.28^{\mathrm{a}}$ \\
\hline Glu (1.0 mM) & $1,231.00 \pm 232.69^{\mathrm{d}}$ & $1,309.00 \pm 230.94^{\mathrm{c}}$ & $341.66 \pm 17.64^{\mathrm{bc}}$ & $451.33 \pm 18.05^{\mathrm{d}}$ & $170.00 \pm 17.32^{\mathrm{a}}$ & $176.66 \pm 14.53^{\mathrm{ab}}$ \\
\hline AlaGln $(2.0 \mathrm{mM})$ & $2,163.00 \pm 144.63^{\mathrm{b}}$ & $2,330.66 \pm 179.98^{b}$ & $374.00 \pm 43.47^{\mathrm{b}}$ & $550.00 \pm 17.32^{\mathrm{b}}$ & $120.00 \pm 5.77^{\mathrm{c}}$ & $140.00 \pm 11.56^{\mathrm{c}}$ \\
\hline GlyGln $(2.0 \mathrm{mM})$ & $2,022.00 \pm 112.32^{\mathrm{c}}$ & $2,528.33 \pm 221.82^{b}$ & $373.03 \pm 53.69^{b}$ & $540.00 \pm 23.09^{\mathrm{bc}}$ & $130.00 \pm 5.77^{\mathrm{bc}}$ & $150.00 \pm 11.56^{\mathrm{bc}}$ \\
\hline $\begin{array}{l}\text { AlaGln+GlyGln } \\
(2.0+2.0 \mathrm{mM})\end{array}$ & $2,638.33 \pm 123.16^{\mathrm{a}}$ & $3,539.67 \pm 168.18^{\mathrm{a}}$ & $589.00 \pm 16.74^{\mathrm{a}}$ & $741.00 \pm 12.12^{\mathrm{a}}$ & $70.00 \pm 11.56^{\mathrm{d}}$ & $100.00 \pm 11.54^{\mathrm{d}}$ \\
\hline $\begin{array}{l}\text { Gln+Glu } \\
\quad(1.0+1.0 \mathrm{mM})\end{array}$ & $1,229.00 \pm 125.28^{\mathrm{d}}$ & $1,398.00 \pm 285.79^{c}$ & $295.00 \pm 28.87^{\mathrm{c}}$ & $487.00 \pm 50.23^{\mathrm{cd}}$ & $150.00 \pm 11.56^{\mathrm{abc}}$ & $170.00 \pm 15.28^{\mathrm{ab}}$ \\
\hline
\end{tabular}

Within a column, values with different letters $(a-d)$ are significantly different $(\mathrm{p}<0.05)$.

$\mathrm{n}$ : number of embryos, five replicates. Mean \pm SEM obtained from the average of each replicate. 
Table 5. Effects of glutamine (Gln), glutamic acid (Glu), L-alaylL-glutamine (AlaGln), L-glycyl-L-glutamine (GlyGln) and their combinations on blastocyst cell number

\begin{tabular}{lccc}
\hline \multirow{2}{*}{ Treatment } & \multicolumn{3}{c}{ Cell numbers (mean \pm SEM) } \\
\cline { 2 - 4 } & ICM & TE & Total \\
\hline Control $(0)$ & $14.00 \pm 1.15^{\mathrm{f}}$ & $22.00 \pm 2.31^{\text {cd }}$ & $36.00 \pm 3.46^{\text {cd }}$ \\
Gln $(1.0 \mathrm{mM})$ & $17.20 \pm 1.17^{\mathrm{d}}$ & $21.00 \pm 1.73^{\mathrm{de}}$ & $38.20 \pm 2.90^{\mathrm{c}}$ \\
Glu $(1.0 \mathrm{mM})$ & $16.86 \pm 1.16^{\mathrm{d}}$ & $23.03 \pm 1.73^{\mathrm{c}}$ & $39.89 \pm 2.89^{\mathrm{c}}$ \\
AlaGln $(2.0 \mathrm{mM})$ & $25.20 \pm 1.74^{\mathrm{b}}$ & $34.00 \pm 1.15^{\mathrm{b}}$ & $59.20 \pm 2.89^{\mathrm{b}}$ \\
GlyGln $(2.0 \mathrm{mM})$ & $23.00 \pm 1.73^{\mathrm{c}}$ & $35.07 \pm 1.73^{\mathrm{b}}$ & $58.07 \pm 3.46^{\mathrm{b}}$ \\
AlaGln+GlyGln & $27.33 \pm 1.45^{\mathrm{a}}$ & $39.00 \pm 1.15^{\mathrm{a}}$ & $66.33 \pm 2.60^{\mathrm{a}}$ \\
$(2.0+2.0 \mathrm{mM})$ & & & \\
Gln+Glu & $15.00 \pm 1.55^{\mathrm{e}}$ & $20.00 \pm 1.15^{\mathrm{e}}$ & $35.00 \pm 2.70^{\mathrm{d}}$ \\
$(1.0+1.0 \mathrm{mM})$ & & & \\
\hline
\end{tabular}

Values shown were obtained based on 30 embryos from three replicates. Within the same column, values with different superscript letters (a-f) are significantly different $(\mathrm{p}<0.05)$

suggest that during in vitro maturation, bovine oocytes have a greater tolerance of high physiological concentrations of ammonia than porcine oocytes. During IVM, cumulus cells are considered to be of vital importance to the success of oocyte maturation (Tanghe et al., 2002). In vitro growth and metabolism of cumulus cells is altered by concentrations of ammonia similar to those measured in follicular fluid, and the ability of these cumulus cells to support in vitro maturation of oocytes is impaired (Rooke et al., 2004). Alternatively, cumulus cells may reduce the amount of ammonia the oocyte is directly exposed to by detoxifying the ammonia in the medium or preventing transport to the oocyte via gap junctions. Our data strongly suggest that the addition of AlaGln+GlyGln has the greatest effect on MII, monospermic fertilization and male pronuclear formation, maturation and fertilization in mTCM-199 and mTALP media.

Amino acids support normal preimplantation development in vivo as evidenced by in vitro studies. Spontaneous degradation and breakdown of amino acids results in the formation of pyrrolidone carbonic acid and potentially harmful ammonia. Ammonia toxicity for living cells is well recognized in vitro and in vivo. Specifically, increased levels of ammonia decrease the $\mathrm{pH}$ and increase the osmolarity, leading to a progressive loss of sperm motility (Kim and Kim, 1998) and decreased the rates of porcine oocyte MII and monospermic fertilization in vitro (Tareq et al., 2007). Our results demonstrate that the accumulation of ammonia was reduced by treatment with AlaGln+GlyGln when compared with those of the other treatment groups. We found that treatment with AlaGln+GlyGln dipeptides may play an important role in reducing the accumulation of ammonia in the culture medium and increase the rates of oocyte maturation, fertilization, and development into blastocysts. Our previous study (Tareq et al., 2007) confirmed the effects of treatment with AlaGln and GlyGln on reducing the accumulation of ammonia in porcine IVM and IVF medium containing exogenous ammonia $(300 \mu \mathrm{M})$, and that these treatments led to an increased rate of nuclear maturation and mono-spermic fertilization in mNCSU-37 media. When compared to the results reported for bovine oocytes, porcine oocytes were found to be more sensitive to the ammonia concentration, as indicated by blastocyst formation. Oocytes of pigs had decreased blastocyst development when induced to a mature state with $200 \mu \mathrm{M}$ ammonia (Yuan and Krisher, 2010). However, it is possible that ammonia accumulated in the oocytes during IVM via $\mathrm{Na}^{+} / \mathrm{K}^{+}$-ATPase or $\mathrm{Na}^{+} / \mathrm{K}^{+} 2 \mathrm{Cl}$ co-transporter (Martinelle and Häggström, 1993).

Several studies have demonstrated the impact of glucose metabolism in mammalian preimplantation embryos, and nutrient uptake studies of porcine embryos have shown that the embryos consume glucose and produce lactate at all stages of development. Therefore, glucose-containing media is commonly used to produce porcine embryos in vitro (Gandhi et al., 2001). The incorporation and oxidation of glucose serve as indicators of the vitality of oocytes and the resulting eggs (Tsujii et al., 2009). In this study, the incorporation and oxidation rates of ${ }^{14} \mathrm{C}(\mathrm{U})$-glucose were significantly higher in AlaGln+GlyGln treated oocytes than in the control group during maturation, fertilization, and the 2-cell and blastocyst stages, which was in agreement with the results of our previous study (Tareq et al., 2012). We reported that the combination of selenium and vitamin $\mathrm{E}$ in comparison with single supplementation improves porcine embryos, which suggests that the incorporation and oxidation rates of ${ }^{14} \mathrm{C}(\mathrm{U})$-glucose were higher in embryos treated with SeMet and SeMet+Vitamin-E at the 2-cell and blastocyst stages. Gardner and Lane (1993) proposed that ammonia may adversely affect the developing embryo by decreasing the concentration of $\alpha$-ketoglutarate by converting it to Gln, thereby reducing the influx through the tricarboxylic acid cycle and depleting ATP production in embryonic cells. Therefore, high ammonia in the culture media at the time of compaction and blastulation may reduce the availability of ATP for embryonic cells during a stage of development when energy demands by the embryo are high, resulting in increased degenerate ova and decreased blastocyst stages. Furthermore, pyruvate may be used as an ammonia sink by transamination to alanine in early embryos (Orsi and Leese, 2004). Gln can also dispose of ammonia by transfer into Gln in blastocysts, but only in the absence of pyruvate available for transamination to alanine (Orsi and Leese, 2004). Gln is the most volatile amino acid and is easily degraded in culture medium, resulting in generation of ammonia (Lane and Gardner, 2003). The amount of ammonia produced by medium 
containing Gln incubated at $37^{\circ} \mathrm{C}$ for $24 \mathrm{~h}$ is sufficient to inhibit embryo development (Lane and Gardner, 2003; Orsi and Leese, 2004; Virant-Klun et al., 2006). One method of reducing toxic ammonia build up is substituting Gln with more stable dipeptides including AlaGln and GlyGln. Substitution of AlnGln for Gln in mouse embryo culture medium results in significantly decreased ammonia concentrations (Lane and Gardner, 2003). This is also an effective way to optimize porcine oocyte IVM, IVF and IVC systems. These results are in agreement with those of other research groups (Biggers et al., 2004). GlyGln has been used to replace Gln in culture medium and is advantageous to mouse embryonic development (Summers et al., 2005). Our findings suggested that AlaGln+GlyGln might protect against the oxidative damage caused by ammonia production. To the best of our knowledge, this is the first study demonstrating that the addition of AlaGln+GlyGln to porcine embryo culture increases the 2 to 4 cell, 8 to 16 cell, morula and blastocyst stages in a defined, Gln-free mNCSU-23 medium. However, the significant increase in the number of ICM and TE cells produced by AlaGln+GlyGln suggests that alanine and glycine produced the primary effect via an unknown mechanism. A routine supplementation of Gln with the more stable form of AlaGln or GlyGln in the culture medium markedly reduced the accumulation of ammonia during blastocyst formation in mice (Eagle, 1955), which is in agreement with the results of the present study. Together, these findings confirm that AlaGln+GlyGln dipeptides are able to inhibit the accumulation of ammonia in culture medium. When tissue is present, ammonia also forms due to the metabolism of Gln (Newsholme and Newsholme, 1989) and other metabolites (metabolic ammonia). The accumulation of ammonia and 2-pyrrolidone-5-carboxylic acid can be reduced by substituting more stable dipeptides that can also be utilized by cells in vitro (Eagle, 1955). It has been suggested that these dipeptides are first hydrolyzed to extracellular peptidase secreted by the cultured cells (Christie and Butler, 1994). Roth et al. (1988) used AlnGln or GlyGin to prevent the deleterious effect of autoclaving RPMI medium, which contains Gln, on the growth of K562 cells. Since their study, these Gln-containing dipeptides have been used to replace Gln in media employed in the culture of other cell types (Christie and Butler, 1994).

In conclusion, the results of our study demonstrate that dipeptides are involved in modulation of porcine oocyte maturation, fertilization and embryo development. The combination of AlaGln+GlyGln may be involved in reducing the accumulation of ammonia, and consequently in increasing the rates of maturation, fertilization, embryo development, and the glucose uptake with the treatment in the porcine embryo. Elsewhere, we have presented evidence that replacing Gln with AlaGln and/or GlyGln, (2.0 mM) which is now being added to several commercial media formulations, can inhibit the accumulation of ammonia in embryo development culture media.

\section{ACKNOWLEDGEMENTS}

This work was supported by the 2012 Yeungnam University Research Grant.

\section{REFERENCES}

Alexiou, M. and H. J. Leese. 1992. Purine utilization, de novo synthesis and degradation in mouse preimplantation embryos. Development 114:185-192.

Biggers, J. D., L. K. McGinnis and J. A. Lawitts. 2004. Enhanced effect of glycyl-L-glutamine on mouse preimplantation embryos in vitro. Reprod. Biomed. Online 9:59-69.

Christie, A. and M. Butler. 1994. Glutamine-based dipeptides are utilized in mammalian cell culture by extracellular hydrolysis catalyzed by a specific peptidase. J. Biotechnol. 37:277-290.

Eagle, H. 1955. Utilization of dipeptides by mammalian cells in tissue culture. Proc. Soc. Exp. Biol. Med. 89:96-99.

Edwards, L. J., D. A. Williams and D. K. Gardner. 1998. Intracellular $\mathrm{pH}$ of the mouse preimplantation embryo: amino acids act as buffers of intracellular pH. Hum. Reprod. 13:34413448 .

Eppig, J. J. and M. J. O'Brien. 1998. Comparison of preimplantation developmental competence after mouse oocyte growth and development in vitro and in vivo. Theriogenology 49:415-422.

Epstein, C. J. and S. A. Smith. 1973. Amino acid uptake and protein synthesis in preimplantation mouse embryos. Dev. Biol. 33:171-184.

Gandhi, A. P., M. Lane, D. K. Gardner and R. L. Krisher. 2001. Substrate utilization in porcine embryos cultured in NCSU23 and G1.2/G2.2 sequential culture media. Mol. Reprod. Dev. 58:269-275.

Gardner, D. K. and M. Lane. 1993. Amino acids and ammonia regulate mouse embryo development in culture. Biol. Reprod. 48:377-385.

Gardner, D. K. 1998. Changes in requirements and utilisation of nutrients during mammalian preimplantation embryo development and their significance in embryo culture. Theriogenology 49:83-102.

Hammon, D. S., S. Wang and G. R. Holyoak. 2000. Ammonia concentration in bovine follicular fluid and its effect during in vitro maturation on subsequent embryo development. Anim. Reprod. Sci. 58:1-8.

Hashem, A., M. S. Hossein, J. Y. Woo, S. Kim, J. H. Kim, S. H. Lee, O. J. Koo, S. M. Park, Lee, E. G., S. K. Kang and B. C. Lee. 2006. Effect of potassium simplex optimization medium and NCSU23 supplemented with beta-mercaptoethanol and amino acids of in vitro fertilized porcine embryos. J. Reprod. Dev. 52:591-599.

Hunter, R. H. and C. Polge. 1966. Maturation of follicular oocytes in the pig after injection of human chorionic gonadotropin. J. 
Reprod. Fertil.12:525-531.

Johnson, L. A., J. G. Aalbers and H. J. G. Grooten. 1988. Artificial insemination of swine: fecundity of boar semen stored in Beltsville TS (BTS), modified Modena (MM), or MR-A and inseminated on one, three and four days after collection. Reprod. Domest. Anim. 23:49-55.

Kim, S. C. and H. W. Kim. 1998. Effects of nitrogenous components of urine on sperm motility: an in vitro study. Int. J. Androl. 21:29-33.

Krisher, R. L., A. M. Brad, J. R. Herrick, M. L. Sparman and J. E. Swain. 2007. A comparative analysis of metabolism and viability in porcine oocytes during in vitro maturation. Anim. Reprod. Sci. 98:72-96.

Lane, M. 2001. Mechanisms for managing cellular and homeostatic stress in vitro. Theriogenology 55:225-236.

Lane, M. and D. K. Gardner. 1994. Increase in postimplantation development of cultured mouse embryos by amino acids and induction of fetal retardation and exencephaly by ammonium ions. J. Reprod. Fertil. 102:305-312.

Lane, M. and D. K. Gardner. 2003. Ammonium induces aberrant blastocyst differentiation, metabolism, $\mathrm{pH}$ regulation, gene expression and subsequently alters fetal development in the mouse. Biol. Reprod. 69:1109-1117.

Lane, M., J. M. Maybach and D. K. Gardner. 2002. Ammonium affects ICM development, metabolism, intracellular $\mathrm{pH}$, and fetal growth rates. Biol. Reprod. 66:104.

Lindenbaum, A. 1973. A survey of naturally occurring chelating ligands. Adv. Exp. Med. Biol. 40:67-77.

Martinelle, K. and L. Häggström. 1993. Mechanisms of ammonia and ammonium ion toxicity in animal cells: transport across cell membranes. J. Biotechnol. 30:339-350.

Newsholme, P. and E. A. Newsholme. 1989. Rates of utilization of glucose, glutamine, and oleate and formation of end-products by mouse peritoneal macrophages in culture. Biochem. J. 261:211-218.

Orsi, N. M. and H. J. Leese. 2004. Ammoniu exposure and pyruvate affect the amino acid metabolism of bovine blastocysts in vitro. Reproduction 127:131-140.

Parrish, J. J., J. Susko-Parrish, M. A. Winer and N. L. First. 1988. Capacitation of bovine sperm by heparin. Biol. Reprod. 38:1171-1180.

Petters, I. W. and M. L. Reed. 1991. Addition of taurine or hypotaurine to culture medium improves development of oneand two-cell pig embryos in vitro. Theriogenology 35:253.

Prior, R. L. and W. J. Visek. 1972. Effects of urea hydrolysis on tissue metabolite concentrations in rats. Am. J. Physiol. 223:1143-1149.

Rooke, J. A., M. Ewen, K. Mackie, M. E. Staines, T. G. McEvoy and K. D. Sinclair. 2004. Effect of ammonium chloride on the growth and metabolism of bovine ovarian granulosa cells and the development of ovine oocytes matured in the presence of bovine granulosa cells previously exposed to ammonium chloride. Anim. Reprod. Sci. 84:53-71.

Roth, E., G. Ollenschlager, G. Hamilton, A. Simmel, K. Langer, W. Fekl and R. Jakesz. 1988. Influence of two glutamine-containing dipeptides on growth of mammalian cells. In Vitro Cell Dev. Biol. Anim. 24:696-698.
Sinclair, K. D., T. G. McEvoy, C. Carolan, E. K. Maxfield, C. A. Maltin, L. E. Young, I. Wilmut, J. J. Robinson and P. J. Broadbent. 1998. Conceptus growth and development following the culture of ovine embryos in media supplemented with sera. Theriogenology 49:218.

Snedecor, G. W. and W. G. Cochran. 1989. Statistical methods. 8th edn. The Iowa State University Press, Iowa.

Summers, M. C., L. K. McGinnis, J. A. Lawitts and J. D. Biggers. 2005. Mouse embryo development following IVF in media containing either L-glutamine or glycyl-L-glutamine. Hum. Reprod. 20:1364-1371.

Tanghe, S., A. Van Soom, H. Nauwynck, M. Coryn and A. de Kruif. 2002. Minireview: functions of the cumulus oophorus during oocyte maturation ovulation, and fertilization. Mol. Reprod. Dev. 61:414-424.

Tareq, K. M. A., A. G. Miah, U. Salma, M. Yoshida and H. Tsujii. 2007. Effect of amino acids and dipeptides on accumulation of ammonia in the medium during in vitro maturation and fertilization of porcine oocytes. Reprod. Med. Biol. 6:165-170.

Tareq, K. M. A., M. S. Hossain, Q. S. Akter, T. Sawada, S. Afrose, K. Hamano and H. Tsujii. 2008. Effect of amino acids and dipeptides on acrosome reaction and accumulation of ammonia in porcine spermatozoa. Reprod. Med. Biol. 7:123-131.

Tareq, K. M. A., Q. S. Akter, M. A. M. Y. Khandoker and H. Tsujii. 2012. Selenium and vitamin $\mathrm{E}$ improve the in vitro maturation, fertilization and culture to blastocyst of porcine oocytes. J. Reprod. Dev. 58:621-628.

Tareq, K. M. A., R. Obata, A. G. Miah, K. Hamano and H. Tsujii. 2005. Ammonia concentration in porcine ovarian developing follicles. J. Mamm. Ova. Res. 22:185-189.

Thouas, G. A., N. A. Korfiatis, A. J. French, G. M. Jones and A. O. Trounson. 2001. Simplified technique for differential staining of inner cell mass and trophectoderm cells of mouse and bovine blastocysts. Reprod. Biomed. Online 3:25-29.

Tsujii, H., M. Muranaka and K. Hamano. 2002. Culture of in vitro mouse embryos with vitamin $\mathrm{E}$ improves development. J. Reprod. Dev. 48:25-29.

Tsujii, H., J. H. Lee, M. S. Hossain, K. M. A. Tareq, K. Hamano and T. Sawada. 2009. The beneficial effect of fructose and glucose on in vitro maturation and the fertilization of porcine oocytes. Reprod. Med. Biol. 8:19-24.

Virant-Klun, I., T. Tomazevic, E. Vrtacnik-Bokal, A. Vogler, M. Krsnik and H. Meden-Vrtovec. 2006. Increased ammonium in culture medium reduces the development of human embryos to the blastocyst stage. Fertil. Steril. 85:526-528.

Visek, W. J., G. M. Kolodny and P. R. Gross. 1972. Ammonia effects in cultures of normal and transformed 3 T3 cells. J. Cell. Physiol. 80:373-381.

Yuan, Y. and R. L. Krisher. 2010. Effect of ammonium during in vitro maturation on oocyte nuclear maturation and subsequent embryonic development in pigs. Anim. Reprod. Sci. 117:302307.

Zander, D. L., J. G. Thompson and M. Lane. 2006. Perturbations in mouse embryo development and viability caused by ammonium are more severe after exposure at the cleavage stages. Biol. Reprod. 74:288-294. 